\title{
Reappraising International Business in a Digital Arena: Barriers, Strategies, and Context for Digital Internationalization
}

\author{
Noman Ahmed Shaheer ${ }^{1}$ \\ 1 The University of Sydney, Australia \\ Keywords: mobile apps, demand-side perspective, location choice, ownership advantage, digital globalization, born-digital firms \\ https://doi.org/10.46697/001c.17849
}

\section{AIB Insights}

Vol. 20, Issue 3, 2020

Born-digital firms face a new set of internationalization challenges. Despite their digital innovations being globally available, born-digital firms still need to satisfy diverse user preferences across countries and stand out against stiff competition to internationalize their digital innovations. Born-digital firms may overcome these challenges by strategically leveraging their users. In particular, acquiring users in certain lead markets can enable born-digital firms to spread global word-of-mouth or upgrade their digital innovations to appeal to users in multiple countries. Hence, born-digital firms should first expand to lead countries that could serve as springboards for global diffusion of their digital innovations.

\section{BIG QUESTION}

What novel strategies born-digital firms can employ to overcome the unique barriers of digital internationalization and accelerate the internationalization of their digital innovations?

\section{INTRODUCTION}

Digitalization is rewriting the fundamental rules of internationalization. For born-digital firms, internationalization is no more a gradual process of committing intensive resources to slowly expand to a few countries. Instead, borndigital firms instantly access globally disperse resources for development of novel digital innovations that are made available to the whole world with just a few clicks. Such advantages are particularly evident for born-digital firms operating their entire value chains online, such as mobile apps, online games, cloud storage, streaming services, and social media platforms (Monaghan, Tippmann, \& Coviello, 2020; Shaheer, Li, \& Priem, 2020). For instance, an app developer stationed in Africa can join an IOS app store by just filling some online forms, access software development kits (SDKs) offered by globally disperse programmers to develop an app, instantly make the app available to users around the world, register across advertising networks in Europe, Americas, and Asia to earn revenues, and use digital currencies, such as bitcoins, for transactions across borders, all without leaving the home country even once. No wonder the world of international business is shifting from atoms and molecules transported through seaports and highways to bits and digits connecting the world through virtual clouds. While cross-border flows in goods, services, and finances declined from 53\% of world GDP in 2007 to only
$39 \%$ in 2015 , global data flows exploded by tenfold to reach 20,000 gigabits per second, 314 million individuals engaged in direct cross-border transactions through online channels, and $80 \%$ of born-digital firms started as global businesses from the onset (BCG, 2017; Mckinsey \& Company, 2016).

The new pathways to digital internationalization bring a novel set of challenges for which traditional international business thinking is inadequate. The variety of digital innovations readily available in all countries makes it difficult for born-digital firms to stand-out against competition. The idea of establishing a stronger position in the favourable environment of the home country is no longer relevant in an era of global competition. Massive resource bases do not necessarily offer a competitive edge as newly established born-digital firms can rely on freely available resources from around the world to counter their resourcerich competitors. Clearly, a new strategic approach is critical for born-digital firms. This article based on my doctoral dissertation contributes in this direction by highlighting the unique challenges of digital internationalization and offering some novel strategies born-digital firms can employ to facilitate the internationalization of their digital innovations.

\section{DEFINING BORN-DIGITAL FIRMS AND DIGITAL INTERNATIONALIZATION}

It is essential to adequately define born-digital firms and digital internationalization before discussing internationalization challenges and strategies for a digital era. While almost every firm is taking advantage of digital technologies, born-digital firms represent a new breed of businesses that can create value only due to digitalization. Hence, born- 
digital firms can be defined as "the firms whose core value proposition is enabled by digital infrastructures". For instance, both Amazon and Walmart are active in the retail sector. However, only Amazon is a born-digital firm as its core value proposition, online ordering and delivery, is not possible without digitalization whereas the main business of Walmart can operate purely offline without any digital technologies.

A wide spectrum of businesses can fall under the definition of born-digital firms. On one end, there are offline products and services traded through digitally enabled business models such as eBay, Amazon, or shared economy firms like Uber. On the other extreme, there are fully digital businesses whose value chains do not include offline components at all. Social media sites, streaming services like Netflix or YouTube, digital distribution platforms like Apple's app store, many mobile apps, and online games may fall in this category. While all born-digital firms may face the unique challenges of digital internationalization and require novel strategies to different extents, this article largely focuses on born-digital firms that operate entire value chains digitally as internationalization of these firms diverges from internationalization of traditional firms by the greatest degree.

The distinctiveness of born-digital firms also requires a reconceptualization of internationalization. Traditional businesses internationalize by making foreign direct investments to take ownership of assets outside their home countries. Such a conceptualization may be less relevant for born-digital firms who can conduct international business on virtual channels without taking ownership of assets. Instead, the most important determinant of the internationalization of born-digital firms is their success in acquiring users across countries, which leads to larger userbases and higher revenues. Accordingly, digital internationalization is defined as "a process of foreign market penetrations in which born-digital firms simultaneously acquire interested users across multiple countries".

\section{THE DISTINCTIVENESS OF DIGITAL INTERNATIONALIZATION}

Digital internationalization requires a critical reappraisal of current international business thinking. According to traditional conceptualizations of the internationalization process (e.g., Dunning's (1988) Eclectic Paradigm), successful internationalization requires substantial firm resources and capabilities (termed as ownership advantages), which firms usually develop by operating for several years in their home countries. Next, firms carefully select foreign locations where ownership advantages are easily transferable. Usually, such locations are countries that are very similar to home countries in culture, regulations, geography and economy. Alternately, firms can expand to locations that could help strengthen current ownership advantages through their natural resources, favourable government policies, or technological advancements (termed as location advantages). Given the high cost of foreign expansions, firms typically expand to only one or a few countries where they take ownership of physical assets to control business operations (termed as internalization). These considerations lead to an internationalization process in which firms initially focus on home countries and only in later stages, gradually expand to neighbouring or similar countries by internalizing physical assets (e.g., Johanson \& Vahlne's (1977) Uppsala Model). Digital internationalization defies many of these conventions as discussed below.

\section{OWNERSHIP ADVANTAGE FOR DIGITAL INTERNATIONALIZATION}

Cultivating an ownership advantage in the home country is relatively less important for digital internationalization as born-digital firms can rely on globally dispersed resources that reside outside organizational boundaries but are readily accessible through digital channels. SDKs, payment systems, monetization services like advertising agencies and other critical resources are widely available over digital channels, even for free. What is still critical is the firm capability to experiment and reconfigure these resources to offer novel digital innovations with innovative business models.

\section{LOCATION FOR DIGITAL INTERNATIONALIZATION}

Born-digital firms depart from traditional location choice criteria. With low or no cost of foreign expansions, borndigital firms can instantly target any country instead of limiting to the home country or similar counties. Similarly, location advantages may not influence the location choice of born-digital firms as they can readily access globally dispersed resources via digital channels regardless of their locations. For instance, the Apple app store exhibits one of the world's most sophisticated innovation ecosystems where thousands of programmers offer millions of SDKs, which app developers creatively recombine to create novel apps. Although both SDK providers and app developers are located across several countries, they seamlessly connect with each other without investing or physically locating in any country and often without even knowing each other's countries of origin.

\section{INTERNALIZATION FOR DIGITAL INTERNATIONALIZATION}

Taking control of physical assets is less of a concern for born-digital firms. Still, international expansion provides born-digital firms valuable access to user networks. Though these networks are not under firm control, born-digital firms govern them through novel mechanisms to gain strategic advantages. Examples include Uber, AirBnB, or Facebook, who reap critical strategic advantages based on their extensive user networks across countries.

While evolving roles of ownership, location and internalization facilitate digital internationalization, they also create a novel set of barriers that require a new strategic thinking toward internationalization as discussed below.

\section{BARRIERS TO DIGITAL INTERNATIONALIZATION}

\section{USER ADOPTION BARRIERS}

For traditional firms, differences across nations act as market entry barriers that discourage firm managers from expanding abroad. While such entry barriers are less relevant for born-digital firms that enjoy global availability of their technologies, digital internationalization is still impeded by substantial user adoption barriers that emanate from differences in user preferences across countries. Due to such differences, digital innovations developed by born-digital firms of a country may appear foreign and irrelevant to users in other countries, which may prevent user adoption in multiple countries and decelerate digital internationalization. It is difficult for born-digital firms to adequately 
understand user preferences across countries and develop digital innovations that could satisfy such a variety of user preferences.

\section{COMPETITIVE BARRIERS}

In the absence of traditional resource-based barriers, the emergence of intense competition serves as an important barrier for digital internationalization. When thousands of born-digital firms flood digital channels with millions of digital innovations, it becomes difficult for any born-digital firm to stand out. Further, the lack of copyright and intellectual property protection encourages competitors to easily copy successful innovations to stop the global expansion of original innovations. An important case is Flappy bird, whose global expansion was thwarted by dozens of cloned apps that were launched just weeks after the success of Flappy bird.

\section{STRATEGIES FOR OVERCOMING BARRIERS AND ACCELERATING DIGITAL INTERNATIONALIZATION}

\section{USERS AS STRATEGIC ADVANTAGES}

While internal resources may not distinguish a born-digital firm from competitors, born-digital firms still differ in the size and composition of their userbases. These differences provide born-digital firms the opportunity to use their users as strategic leverage to overcome digital internationalization barriers and accelerate internationalization of their digital innovations.

Born-digital firms can harness three strategic advantages from their users. First, born-digital firms may leverage their current users to spread word-of-mouth about their digital innovations to new users in multiple countries. It helps the born-digital firm stand out against competitors by reaching the unique collection of its current users. Second, borndigital firms may engage users in creating diverse content for their digital innovations. While born-digital firms may not be able to understand and address diverse preferences across countries, users can help generate more diverse content that could appeal to multiple countries. Examples are Facebook and YouTube whose users have created such diverse content in which people from every country can find something appealing. Finally, born-digital firms can monitor real-time interactions between their digital innovations and users to continuously upgrade innovations to appeal to more users across countries. For instance, gaming app developer, Zynga, extracts many petabytes of daily data from user interactions with its games, which helps Zynga refresh its games several hundred times each day to better address user needs.

\section{ENGAGING WITH USERS FROM RIGHT LOCATIONS}

Strategically leveraging any type of user may not necessarily accelerate digital internationalization. Users across countries differ in their connections with potential users in other countries, their ability to produce content that is also appealing outside their own countries, and their propensity to help born-digital firms evolve towards developing globally appealing innovations instead of nationally idiosyncratic ones. Hence, it is critical for born-digital firms to cultivate userbases in countries where users could contribute in enhancing the global footprints of their digital innovations.
For born digital firms, two types of countries can act as lead markets, defined as countries where local demand environments induce innovations that could expand across multiple countries. The first type of lead market is countries that share similar preferences with a large number of other countries, termed as countries with high preference overlaps. As users in cyberspace connect with each other based on similar preferences, users from countries with high preference overlaps are likely to have connections with users in several countries, which may facilitate a wider spread of word-of-mouth. The content created by users from such countries also finds appeal in several countries that share similar preferences. Similarly, digital innovation that evolves to address user preferences in countries with high preference overlaps automatically becomes suitable for other countries with similar preferences.

The second type of lead market is countries with high diversity of user preferences, termed as lead markets with preference heterogeneity. Evolving digital innovations to address diverse user preferences in such countries requires born-digital firms to coherently blend a variety of features in their digital innovations. The resulting innovations are so versatile that they can cultivate a broader global appeal. Such creative re-combinations also overcome differences in user preferences across countries as users tend to switch from country-specific digital innovations to converge on superior, more versatile ones. For instance, one important reason behind the global success of role playing games targeting North American markets is the diversity of user preferences in North America, which led game developers to combine diverse elements such as action, stealth, and story-telling in a single game, thereby suiting varying user preferences across several new countries.

\section{RETHINKING THE INTERNATIONALIZATION PROCESS: HOME MARKET TO LEAD MARKETS}

Overcoming user adoption and competitive barriers by strategically leveraging users from certain countries leads to a new approach toward internationalization process. Traditional international business thinking suggests that firms start from the familiar base of their home country and gradually expand to countries that are similar to the home country. Another possibility for born-digital firms is to take advantage of their global accessibility by targeting global markets from inception. While both approaches have their own merits, born-digital firms with international ambitions can start from lead markets, where strategically leveraging users can help expand their global footprints. An important case is the Finnish firm, Supercell, which aims at developing games with a global appeal, so users from any country could enjoy them. Instead of immediately targeting the global market, however, Supercell first penetrates its games in North America and targets other countries only after carefully monitoring the interaction of its games with North American users and making necessary upgrades to improve their global appeal. The global success of Supercell's games like Hay Day and Clash of Clans - which Supercell initially introduced only in North America and only later expanded to other countries - indicates that North America is serving as an effective lead market for Supercell.

\section{CONCLUSION}

Digitalization challenges many core assumptions on which 
traditional international business thinking is based. The main pillars of internationalization strategy - the primacy of resources, the increased costs and risks of entering countries that are very different from home countries, and the need for owning physical assets - are under question in a digital era. Clearly, many traditional approaches for operating international businesses may not provide the best opportunities for sustained growth to born-digital firms. Instead, a concrete understanding of the novel principles of digital globalization is becoming the new source of global competitive advantage. Companies that have learned how to carve out markets in this digitally connected world are building global businesses at an astonishing speed. Uber penetrated more than 80 countries in just six years, with little investment in physical assets, by reaching digitally connected consumers through its global platform. Pokémon Go was being played in almost 150 countries and generated nearly $\$ 1$ billion in global revenue within six months after its launch. Netflix penetrated more than 190 countries in just seven years with its digital streaming service. Clearly, the new rules of digital globalization that require firms to focus on users instead of resources, go beyond home countries to tap countries with strategic advantages, and continuously upgrade innovations to stay ahead of emerging competition instead of searching for a dominant design, offer the recipe of success for the modern digital era.

\section{ACKNOWLEDGEMENTS}

I sincerely thank my PhD supervisor, Sali $\mathrm{Li}$, as well as other members of my dissertation committee, Tatiana Kostova, Richard Priem, and Omrane Guedhami, for their guidance and mentorship. I also thank industry experts, app developers, venture capitalists, and corporate executives who shared their insights with me, particularly during Apple's Worldwide Developers Conference, 2018. Finally, I acknowledge the immense contribution of my family members, particularly my uncle, Dr. Muhammad Naeemullah Naeem, and wife, Rida Raza, whose encouragement and support enabled me to achieve these milestones. This dissertation was funded by the Center for International Business Education and Research, University of South Carolina.

\section{ABOUT THE AUTHOR}

Noman Shaheer (noman.shaheer@sydney.edu.au) is a Lecturer (Assistant Professor) in International Business Department at the University of Sydney. His research focuses on digital strategies, internationalization, and innovation. He has published papers in Journal of International Business Studies, Journal of Business Venturing, and Journal of International Marketing, among others. His research has received several awards including Alan M. Rugman Most Promising Scholar Award, AIB/Temple Best Paper Award, Buckley \& Casson AIB Dissertation Award and AOM IM Division award for Best Dissertation in International Management.

Submitted: August 14, 2020 EST, Accepted: October 26, 2020 EST

This is an open-access article distributed under the terms of the Creative Commons Attribution 4.0 International License (CCBY-4.0). View this license's legal deed at http://creativecommons.org/licenses/by/4.0 and legal code at http://creativecommons.org/licenses/by/4.0/legalcode for more information. 


\section{REFERENCES}

BCG. 2017. The New Globalization: Going Beyond the Rhetoric. BCG Henderson Institute.

Dunning, J. H. 1988. The eclectic paradigm of international production: A restatement and some possible extensions. Journal of International Business Studies, 19(1): 1-31.

Johanson, J., \& Vahlne, J. E. 1977. The internationalization process of the firm-a model of knowledge development and increasing foreign market commitments. Journal of International Business Studies, 8: 23-32.
Mckinsey \& Company. 2016. Digital globalization: The new era of global flows. San Francisco: McKinsey Global Institute.

Monaghan, S., Tippmann, E., \& Coviello, N. 2020. Born digitals: Thoughts on their internationalization and a research agenda. Journal of International Business Studies, 51(1): 11-22.

Shaheer, N., Li, S., \& Priem, R. 2020. Revisiting location in a digital age: How can lead markets accelerate the internationalization of mobile apps? Journal of International Marketing, 1069031X20949457: 1069031-20949457. 